\title{
Investigation of thermochemical Features of Gamma Irradiated Tryptophan Stereoisomers
}

\author{
Ana Neacsu $^{1 *}$, Daniela Gheorghe ${ }^{1}$, Victorita Tecuceanu $^{2}$, Ştefan Perişanu ${ }^{3}$ \\ ${ }^{1}$ Institute of Physical Chemistry "Ilie Murgulescu", 202 Spl. Independentei, 060021, Bucharest, Romania. \\ ${ }^{2}$ Institute of Organic Chemistry "C.D. Nenitzescu" of Romanian Academy, 202B Spl. Independentei, PO Box \\ 15-258, 060023, Bucharest, Romania. \\ ${ }^{3}$ Department of General Chemistry, Polytechnic University of Bucharest, 1 Polizu st.
}

*Corresponding author: Ana Neacsu, email: anna matache@yahoo.com; Phone: (004)021 318 85 95; Fax: (004)0213121147.

Received July 12 $2^{\text {th }}$ 2021; Accepted October $18^{\text {th }}, 2021$.

DOI: http://dx.doi.org/10.29356/jmcs.v66i1.1627

\begin{abstract}
In this work, the use of differential scanning calorimetry (DSC) is demonstrated as a powerful technique that can provide accurate thermodynamic property values of nutritional supplements such as tryptophan. Nutritional supplements require a decontamination procedure and irradiation appears as a promising technique for this purpose. The valuable properties of tryptophan for food and pharmaceutical industry as dietary supplement have led to increasing interest in its technological behaviour. L-, D- isomers and DL-racemic mixture of tryptophan irradiated and non-irradiated were studied by DSC. Irradiation was performed at room temperature with gamma radiations using a ${ }^{137} \mathrm{Cs}$ source, the irradiation dose range was between 0.6 - $10 \mathrm{kGy}$. Two steps decomposition pattern for both irradiated and non-irradiated samples up to $350{ }^{\circ} \mathrm{C}$ was found. Fourier transform infrared spectroscopic studies were performed. The obtained results indicate that the irradiation process does not inhibit the thermal properties of tryptophan when irradiated up to $10 \mathrm{kGy}$. The HPLC method was employed to evidence the degradation of the irradiated material.
\end{abstract}

Keywords: Tryptophan isomers; DSC; FTIR; HPLC; gamma irradiation.

Resumen. En este trabajo, se demuestra el uso de calorimetría diferencial de barrido (DSC) como una técnica poderosa que puede proporcionar valores precisos de propiedades termodinámicas de suplementos nutricionales como el triptófano. Los suplementos nutricionales requieren un procedimiento de descontaminación y la irradiación aparece como una técnica prometedora para este propósito. Las valiosas propiedades del triptófano para la industria alimentaria y farmacéutica como suplemento dietético han provocado un creciente interés por su comportamiento tecnológico. Los isómeros L-, D- y la mezcla racémica DL- de triptófano irradiado y no irradiado fueron estudiados por DSC. La irradiación se realizó a temperatura ambiente con radiaciones gamma utilizando una fuente de ${ }^{137} \mathrm{Cs}$, el rango de dosis de irradiación estuvo entre $0.6-10 \mathrm{kGy}$. Se encontró un patrón de descomposición de dos pasos para muestras irradiadas y no irradiadas hasta $350{ }^{\circ} \mathrm{C}$. Se realizaron estudios espectroscópicos de infrarrojos por la transformada de Fourier. Los resultados obtenidos indican que el proceso de irradiación no inhibe las propiedades térmicas del triptófano cuando se irradia hasta $10 \mathrm{kGy}$. Se empleó el método HPLC para evidenciar la degradación del material irradiado.

Palabras clave: Isómeros de triptófano; DSC; FTIR; HPLC; irradiación gamma. 


\section{Introduction}

Tryptophan is a heterocyclic amino acid (see below formula) being an essential plant-derived amino acid that is necessary for the in vivo biosynthesis of proteins. It must be therefore synthesized from the diet [1]. Tryptophan has an indole side chain; thus, it is considered a non-polar aromatic amino acid [2].

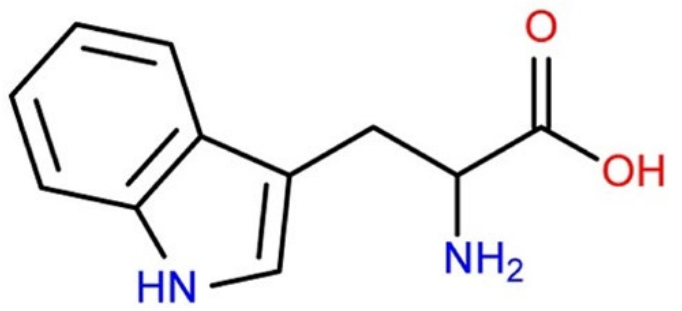

Scheme 1. The chemical structure of tryptophan.

It is involved in nitrogen balance in adults and growth in infants, is being found in fortified infant foods and corn tortillas and have possible function in the diagnosis and mitigation of multiple human diseases [3]. It also produces niacin, which is essential in creating the neuro-transmitter serotonin which is synthesized via tryptophan hydroxylase. It can be also metabolized into melatonin (a hormone allowing the entrainment of the circadian rhythms of several biological functions) as well as into vitamin B3 (nicotinic acid) [4]. D-Tryptophan is sometimes found in peptides that have been produced naturally [5].

The valuable properties of tryptophan for food and pharmaceutical industries have led to increasing interest in its technological behaviour. For this purpose, we have carried out the present study of the physicochemical characterization of tryptophan isomers for biomedical applications. A necessary condition for the use of bioproducts and pharmaceuticals is an adequate sterilization. A sterilization technique is provided by gamma irradiation which is known to cause structural modification such as scission and crosslinking in irradiated compounds. Random chain scission is found to be the main chemical process occurring during radiation sterilization [6].

Amino acids exist as zwitterionic species in the crystalline state. In solution their structure is $\mathrm{pH}$ dependent. When irradiated, radicals in a zwitterionic form can be formed. Amino acid radicals are involved in many biological reactions [7-9].

This paper presents the results of thermal analysis applied to the study of the effects of irradiation treating on tryptophan isomers, which demonstrate that some changes in the thermal behaviour could occur in products after irradiation. The parameters associated with the behaviour on heating, namely the temperatures and enthalpies of melting/decomposition, the purity by DSC, the mass loss by TG were evaluated. In the present work the consequences of the irradiation process of the studied compounds, were investigated by the ESI-mass spectrometry MS method.

The use of MS is important to provide complementary information to the DSC data, to identify the radiolysis products including those which can keep a chiral centre and to perform a quantitative analysis of irradiation products. compounds.

The results of the present measurements were compared to those for the same non-irradiated

The primary processes taking place on irradiation consists in oxidation and reduction, followed by transformation of the molecules in radical cations and anions due to the expulsion or capture of electrons, respectively, under the action of radiations. These entities are changing through decarboxylation, deamination, deamidation and dehydrogenation processes into another radicalic species in various concentrations. These species have different thermal resistance due to their differences in structure. Radicals disappear with rising temperature because their mobility increases on heating and the possibility arrises for them to be involved in processes such as recombination, decomposition and reactions with neighbour parent molecules [10]. 
Mass spectrometry technique is used to identify some of the radiation products. The radiolysis products detected in the normal mass range are consequences of radicals assembling processes. Tryptophan was wrecked into radicals due to the high energy developed in the radiolysis process. The radicals could react via different pathways: react with each other, react with neutral molecules or rearrange. The interaction with another radical or a neutral molecule led to the formation of products with a higher molecular mass than the amino acid itself [11].

This study was undertaken in order to check if thermal analysis such as differential scanning calorimetry (DSC) is suitable for testing the effect of radiation sterilization on tryptophan, to establish the adequate irradiation dose for sterilization and to compare the results obtained by this method with those obtained by FTIR, MS and HPLC.

The proposed compounds for this study have biological importance as building blocks of proteins. As tryptophan is included in many synthetic and natural products involved in pharmaceutical and food industry, the results of our research will serve as a start and a model in subsequent approach of more complex systems, namely peptides.

\section{Experimental}

\section{Materials}

The amino acids studied in this work were obtained commercially as follows: D-, and DL-tryptophan from Sigma-Aldrich (mass fraction purities $\geq 98 \%$ ) and L-tryptophan for biochemistry from Merck. The three materials were used after drying them in a vacuum oven for 3 hours at $90{ }^{\circ} \mathrm{C}$ in order to eliminate adsorbed water. They were preserved in a desiccator afterwards.

\section{Methods \\ Irradiation}

Gamma rays used for pharmaceuticals and adjuvants sterilization are generated by radioactive isotopes (either ${ }^{60} \mathrm{Co}$ or ${ }^{137} \mathrm{Cs}$ ), which upon decay, emit gamma rays of high energy and excellent penetrating power ( capacity to penetrate the target product up to several feet). The calculation of the dose in a point outside a cylindrical source was discussed and its specific activity was defined according to detailed mathematical formulas in our previous works. It was taken into account self absorption and radiation attenuation in the space between the source and the interest point. The absorbent environment was considered to be the air [12-13].

$\mathrm{A}^{137} \mathrm{Cs}$ source with an activity of $3 \cdot 10^{13} \mathrm{~Bq}$ and a dose rate of $1.05 \cdot 10^{2} \mathrm{~Gy} \mathrm{~h}^{-1}$ was used for $\gamma$-irradiation of L, D and DL tryptophan at room temperature. The adsorbed doses ranged between 0.63 and $10 \mathrm{kGy}$. The studied compounds were white fine crystallite powders prior to irradiation. No modification of the appearance of samples was observed after irradiation.

\section{Differential scanning calorimetry}

A Perkin Elmer power compensated DSC (model 8500) was used for the measurement of the enthalpies and temperatures of the processes occurring during heating (fusion and decomposition). The calorimeter was calibrated with indium $\left(\Delta_{\text {fus }} H=28.46 \mathrm{~J} \mathrm{~g}^{-1}\right)$. The areas of the peaks corresponding to the standard and studied substances were used to calibrate the instrument and calculate the thermal effects of the investigated processes, respectively. Samples of about 1-2 mg of amino acid were sealed in aluminum pans. All samples were scanned at a heating rate of $10{ }^{\circ} \mathrm{C} / \mathrm{min}$, in flowing nitrogen atmosphere (purity $>99.996 \%, 20 \mathrm{~mL} \mathrm{~min}{ }^{-1}$ ) from room temperature to a temperature exceeding the "melting" point $350^{\circ} \mathrm{C}$. The heat flow curves were processed by means of Pyris Software for Windows for calculating the thermal effects, namely melting/decomposition enthalpies and also for evaluating purity.

\section{Thermogravimetry}

For determining the mass loss, a TGA-DTA/DSC SETSYS Evolution 17 analyzer was used in the temperature range from 20 to $350^{\circ} \mathrm{C}$, with a scanning rate of $10{ }^{\circ} \mathrm{C} / \mathrm{min}$, in alumina crucibles, using $\mathrm{Ar}$ flow. 


\section{Fourier transform infrared (FTIR) spectroscopic determinations}

The IR spectra of tryptophan isomers were recorded in solid state, at $298.15 \mathrm{~K}$, in the wave number range $600-3600 \mathrm{~cm}^{-1}$, using a Thermo Scientific Nicolet iS10 FT-IR spectrometer with an attenuated total reflection (ATR) method.

\section{Liquid chromatography coupled to mass spectrometry (LC-MS) method}

The identification and quantification of selected amino acid in the irradiated sample was performed by high performance liquid chromatography (HPLC) using a Varian 310-MS LC/MS/MS triple quadrupole mass spectrometer (USA) fitted with an electrospray ionization interface (ESI). Chemical characterization was carried out by using a VARIAN Inertsil Si column $(150 \times 4.6 \mathrm{~mm}, 5 \mu \mathrm{m}$ particle size $)$. The mobile phases consisted of $100 \mathrm{mM}$ ammonium formate in bidistilled water (brought to $\mathrm{pH}=3$ with formic acid) (A):90 \% acetonitrile $/ 10 \% 200 \mathrm{mM}$ ammonium formate in bidistilled water $(\mathrm{B})=50: 50$, in an isocratic elution. The flow rate, at any time, was $0.6 \mathrm{~mL} / \mathrm{min}$, the injection volume was $20 \mu \mathrm{L}$ and quadruplicate injections were used for each sample. The drying gas was air at a pressure of $131 \mathrm{kPa}$ and $200{ }^{\circ} \mathrm{C}$, and the nebulizing gas was nitrogen at $276 \mathrm{kPa}$. The capillary voltage was set at the potential $5000 \mathrm{~V}$ for positive ionization. The resulting protonated molecular ion was selected by the first quadrupole; in the second quadrupole, the protonated molecular ion was fragmented by collision with an inert gas (argon) at a pressure of $0.2 \mathrm{~Pa}$; the fragments were analyzed in the third quadrupole. Prior to these experiments, the tuning of the mass spectrometer was performed using a polypropylene glycol standard for both positive and negative modes.

L-Tryptophan, D-Tryptophan and DL-Tryptophan were used as standards. $1 \mathrm{~mL}$ of each $0.1 \mathrm{mg} / \mathrm{mL}$ stock solution of mentioned standards in $100 \mathrm{mM}$ ammonium formate in bidistilled water $(\mathrm{pH}=3)$ was brought to $100 \mathrm{~mL}$ with $50 \%$ acetonitrile $/ 50 \% 100 \mathrm{mM}$ ammonium formate in bidistilled water $(\mathrm{pH}=3)$ in a volumetric flask. Thus, the concentration for each standard was $1 \mu \mathrm{g} / \mathrm{mL}$. The same procedure was applied to the irradiated samples.

To optimize the multiple reaction monitoring (MRM) sensitivity, $1 \mathrm{~mL}$ of each $1 \mu \mathrm{g} / \mathrm{mL}$ standard solution was infused at a rate of $10 \mu \mathrm{L} / \mathrm{min}$ with a Harvard 11 plus syringe pump (Harvard Apparatus, South Natick, MA). The drying gas was air at a pressure of $131 \mathrm{kPa}$ and $200^{\circ} \mathrm{C}$, and the nebulizing gas was nitrogen at $276 \mathrm{kPa}$. The capillary voltage was set at the potential $5000 \mathrm{~V}$ for positive ionization. After registry the full scan chromatograms, the breakdown curves to optimize the collision energy for the parent mass of each standard were created. The resulting protonated molecular ion was selected by the first quadrupole; in the second quadrupole, the protonated molecular ion was fragmented by collision with an inert gas (argon) at a pressure of $0.2 \mathrm{~Pa}$; the fragments were analyzed in the third quadrupole. In that way it was generate the relative intensity of the products ions versus Q2 collision energy. Based on these results, it was created for each standard a method to identify the products ions at their specific collision energy. A sequence of injection of standard, followed by an injection of irradiated compound, was repeated four times to generate the quantitative results.

\section{Results and discussion}

\section{Identification of the compounds by FTIR}

In order to obtain information about the irradiation yields, the FT-IR spectra of the compounds before and after irradiation were recorded at room temperature. The FT-IR spectra for L-, D- and DL- tryptophan 12hirradiated (1.26 kGy), relative to the spectra of non-irradiated compounds are shown in Fig. 1. Little significant changes between the recorded spectra were noted. The generated intermediary irradiation yields were negligible. The changes were noticed in the magnitude of the recorded peaks.

The FTIR spectra of pure tryptophans were recorded in the range 3800 to $600 \mathrm{~cm}^{-1}$. (Fig. 1) The characteristic groups of tryptophan were detected by FT-IR spectroscopy. In the literature [14-16] FTIR spectrum of pure tryptophan, the strong absorption peaks at $3400,3000,1410,1357,1059$ and $744 \mathrm{~cm}^{-1}$ are assigned to $\mathrm{N}-\mathrm{H}$ stretching in amines, $\mathrm{O}-\mathrm{H}$ stretching in carboxylic acids, $\mathrm{N}-\mathrm{H}$ bending in amines, $\mathrm{C}-\mathrm{H}$ bending in alkanes, $\mathrm{C}-\mathrm{N}$ stretching in aryl amines and $\mathrm{C}-\mathrm{H}$ bending in aromatic ring, respectively. 

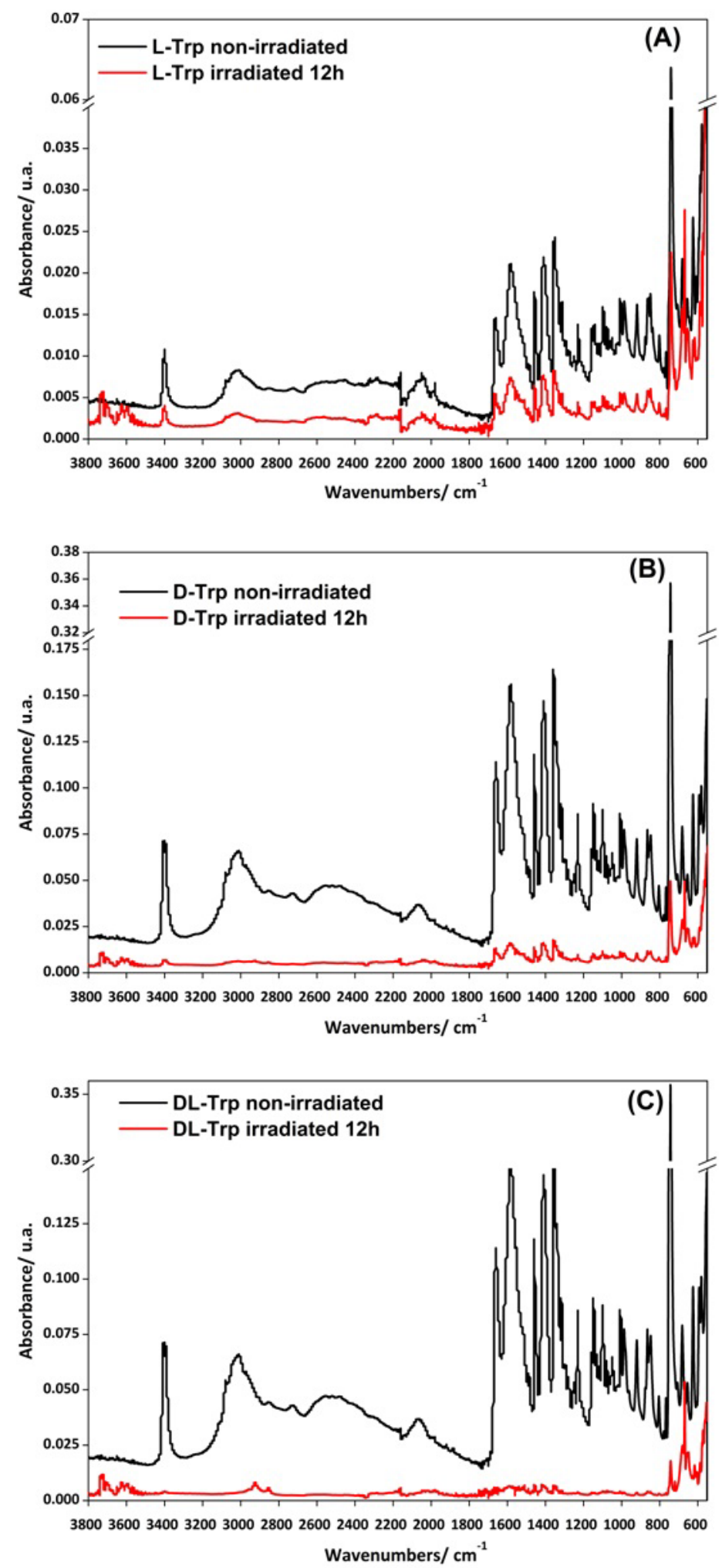

Fig. 1. FTIR spectra of $12 \mathrm{~h}(1.26 \mathrm{kGy})$-irradiated and non-irradiated L-, D- and DL- tryptophan. 
The decrease in the intensity of the peaks for the irradiated tryptophan when compared with pure tryptophan is followed by an increase in their broadness in all the cases at 1558 and $1411 \mathrm{~cm}^{-1}$. The absorption band is weak at $742 \mathrm{~cm}^{-1}$ and the disappearance of a peak at $3037 \mathrm{~cm}^{-1}$ suggests that $\mathrm{N}-\mathrm{H}$ stretching is absent. These observations led us to conclude that the indole ring is not affected by irradiation while both amino and carboxyl groups of tryptophan were the terminal groups preferentially affected by irradiation. As the side chain of the tryptophan molecule is formed of an indole group containing a nitrogen atom, it is likely to consider that these primary amine groups are involved in the interaction of the amino acid with ionizing radiation.

The FT-IR spectrum of L-tryptophan shows an absorption band due to the $\mathrm{N}-\mathrm{H}$ stretching vibrations of the indole ring at $3400 \mathrm{~cm}^{-1}$ apart from the absorption bands due to aliphatic $\mathrm{C}-\mathrm{H}$ bonds and the $\mathrm{C}=\mathrm{O}$ bond of the carboxylic acid group at $2900 \mathrm{~cm}^{-1}$ [17].

The literature [18-19] states that for zwitterionic amino acids the band assigned to the asymmetric stretching of the anionic carboxyl group $-\mathrm{CO}_{2}{ }^{-}$, has a characteristic frequency in the region $1650-1600 \mathrm{~cm}^{-1}$. In our case it is situated at $1662 \mathrm{~cm}^{-1}$, for the non-irradiated samples, and for the irradiated ones at $1635 \mathrm{~cm}^{-1}$ and $1653 \mathrm{~cm}^{-1}$ respectively. The presence of the asymmetric stretching of the $-\mathrm{CO}_{2}^{-}$group shows that the carboxyl group of tryptophan is present in the ionized form $-\mathrm{CO}_{2}^{-}$.

Cao et al. [19] reported the band at $3387 \mathrm{~cm}^{-1}$ as due to indole NH stretching. The bands at 3392 for irradiated and $3400 \mathrm{~cm}^{-1}$ for non-irradiated samples lead to the conclusion that the indole $\mathrm{NH}$ band is not affected by irradiation.

Bending of the indole ring $\mathrm{CH}$ bonds at $740 \mathrm{~cm}^{-1}$ are present both for irradiated and non-irradiated samples; the band at $1576 \mathrm{~cm}^{-1}$ for irradiated and non-irradiated Trp are assigned to vibrations in the main chain, that is of the $-\mathrm{NH}_{3}{ }^{+}$group.

Analysing the recorded spectra, gamma radiation with doses between 0.6-10 kGy does not produce significant changes in the physical-chemical properties of L-tryptophan. The similarity between the samples before and after irradiation highlight that their vibrational spectra preserve the zwitterion features. Some of the bands present in the non-irradiated D- and DL-tryptophan samples disappear after irradiation, proving their different behavior comparing to L-isomer. A common feature for the three isomers is the disappearance of the amino and carboxyl groups after irradiation, which highlights the decarboxylation and deamination processes, also evidenced through MS technique.

\section{Irradiation products}

The MS-MS spectra of tryptophan isomers are presented in Fig. 2. They show that free radicals are formed in the molecular crystal after amino acids irradiation in solid state and that decomposition of the pure amino acid, due to a deamination or a decarboxylation reaction is present [20]. The radiolysis products present low mobility and cannot escape simply. Particularly, important amounts of molecular fragments remain trapped in the crystalline lattice [21]. The liquid chromatographic-tandem mass spectrometer employing electrospray ionization (ESI) source is a powerful tool that can specifically, sensitively and simultaneously identify and quantify many biological compounds [22]. ESI is known as a soft ionization technique because there is little fragmentation.

We recorded the mass spectra of L-, D- and DL-tryptophan isomers non-irradiated and irradiated in the positive mode because these compounds are barely detectable in negative mode. The precursor peak for tryptophan is the corresponding protonated molecular ion $[\mathrm{M}+\mathrm{H}]^{+}, \mathrm{m} / \mathrm{z} 205$. The major collision-induced fragments were identified for all isomers and their spectral sensitivities individually optimized. The $\mathrm{m} / \mathrm{z}$ range monitored was between 205 (precursor ion) and 188, 146 and 118 (products ions). In positive ion ESI, analyte adducts with sodium $[\mathrm{M}+\mathrm{Na}]$, potassium $[\mathrm{M}+\mathrm{K}]$, or other cationic species are often observed. Some background concentration of salt, usually sodium, is almost always present in ESI samples. Low concentrations of sodium (on the order of $10^{-6} \mathrm{M}$ ) can derive from glassware and storage bottles or can be present as impurities - even in analytical grade solvents [23]. A bis adduct of tryptophan Trp-Trp was observed at $\mathrm{m} / \mathrm{z} 409.2$.

The recorded mass spectra of the tryptophan isomers are very close one to another and from Fig. 2 it can be ascertained that there is no significant modification due to irradiation. This demonstrate that radiolysis products are not formed in significant concentration to modify the physico-chemical properties of tryptophan isomers. 

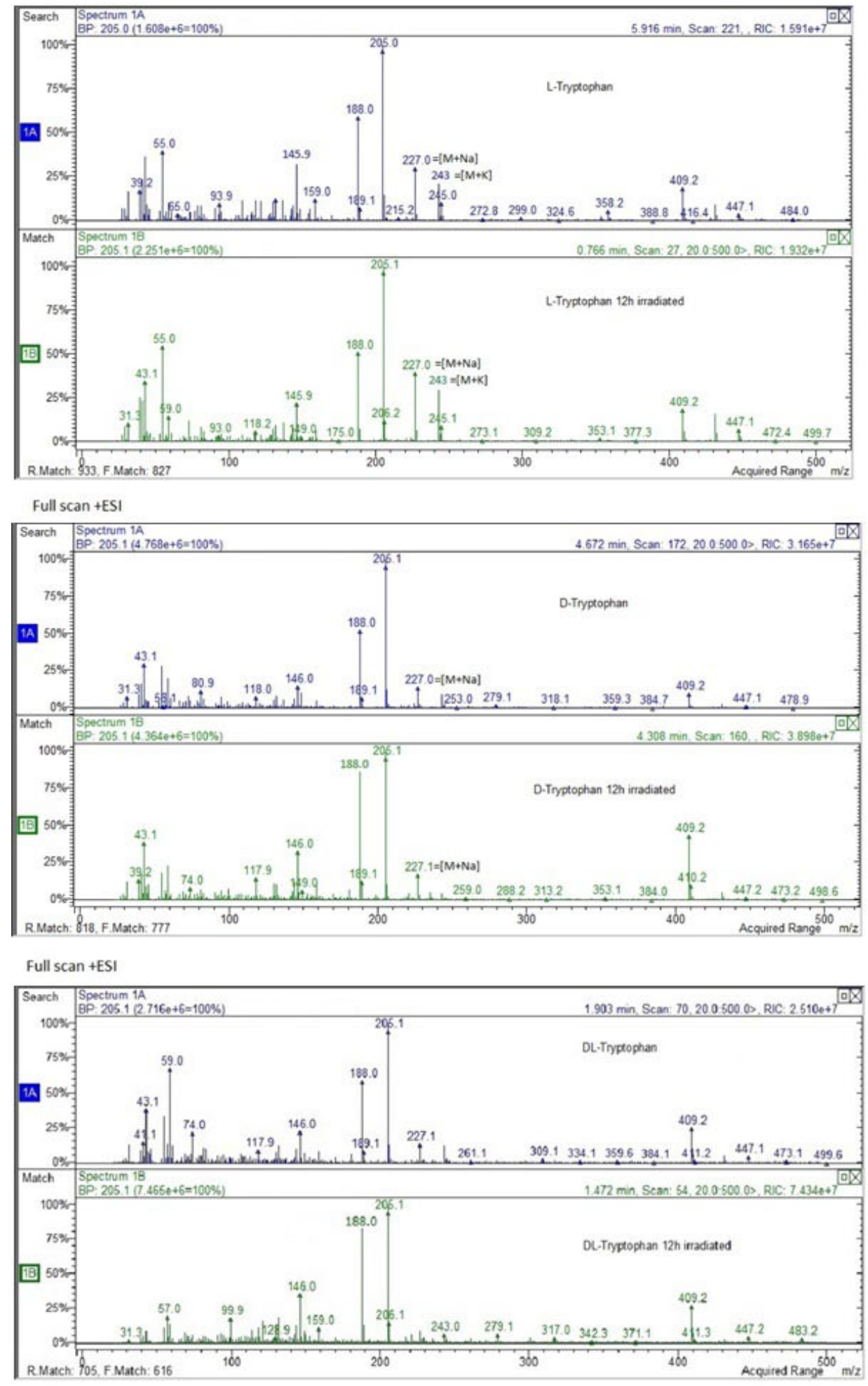

Full scan +ESI

Fig. 2. The MS-MS spectra of L-, D- and DL- tryptophan isomers non-irradiated and irradiated. 
The compounds were ionized using an electrospray source in preparation for mass spectroscopy and detected in the MRM (multiple reaction monitoring) mode.

Multiple reaction monitoring (MRM, also known as Selective Reaction Monitoring - SRM) is a highly specific and sensitive mass spectrometry technique that can selectively quantify compounds within complex mixtures. This technique uses a triple quadrupole MS that firstly targets the ion corresponding to the compound of interest with subsequent fragmentation of that target ion to produce a range of daughter ions. One (or more) of these fragment daughter ions can be selected for quantitation purposes. Only compounds that meet both these criteria, i.e., specific parent ion and specific daughter ions corresponding to the mass of the molecule of interest are isolated within the mass spectrometer. By ignoring all other ions that flow into the mass spectrometer the experiment gains sensitivity, whilst maintaining exquisite accuracy.

MRM is performed for selection of specific analytes and absolute quantitation of proteins, peptides, metabolites and lipids from plasma, serum and other biological samples [24].

The results obtained after MRM quantitative LC-MS/MS analysis are presented in Table 1.

Table 1. Quantitative LC-MS/MS analysis of tryptophan isomers.

\begin{tabular}{|c|c|}
\hline \multicolumn{2}{|c|}{ Quantitative LC-MS/MS analysis } \\
\hline Isomer & $\begin{array}{c}\text { Amount determined } \boldsymbol{\mu g} \\
\text { standard/1 mg IS }\end{array}$ \\
\hline L-Tryptophan & $865.736 \pm 1.5013$ \\
\hline D-Tryptophan & $954.290 \pm 1.6128$ \\
\hline DL-Tryptophan & $988.723 \pm 0.2582$ \\
\hline
\end{tabular}

The concentration of standard in irradiated samples was calculated with the formula (1):

$$
\mathrm{A}_{\text {standard }} / \mathrm{C}_{\text {standard }}=\mathrm{A}_{\text {sample }} / \mathrm{C}_{\text {sample }}
$$

where: $A_{\text {standard }}$ is integrated area of the peak for each standard; $C_{\text {standard }}$ is the known concentration of standard; $\mathrm{A}_{\text {sample }}$ is the integrated area of the peak for each irradiated sample; $\mathrm{C}_{\text {sample }}=$ concentration of standard determined in the irradiated sample.

The analysis of each sample was performed in quadruplicate injections and SD (standard deviation) values were given. The data from Table 1 are in fare agreement with the mass loss plotted in Figure 4 and the purity values from Table 4 . A low concentration of non-irradiated sample indicates a high concentration of radiolysis products.

\section{Thermochemical behavior of the non-irradiated and irradiated tryptophan isomers.}

DSC thermograms of the three isomeric tryptophans non-irradiated and irradiated were recorded in sealed crucibles with non pierced lids (Fig. 3).

The DSC data reveal information about the bioavailability of drugs, their toxicity and the thermal stability. The DSC curves of the substances of low stability and undergoing degradation easily show a characteristic shift of the melting point towards the lower temperatures because degradation products act as contamination and decrease the melting point of drugs [25]. 

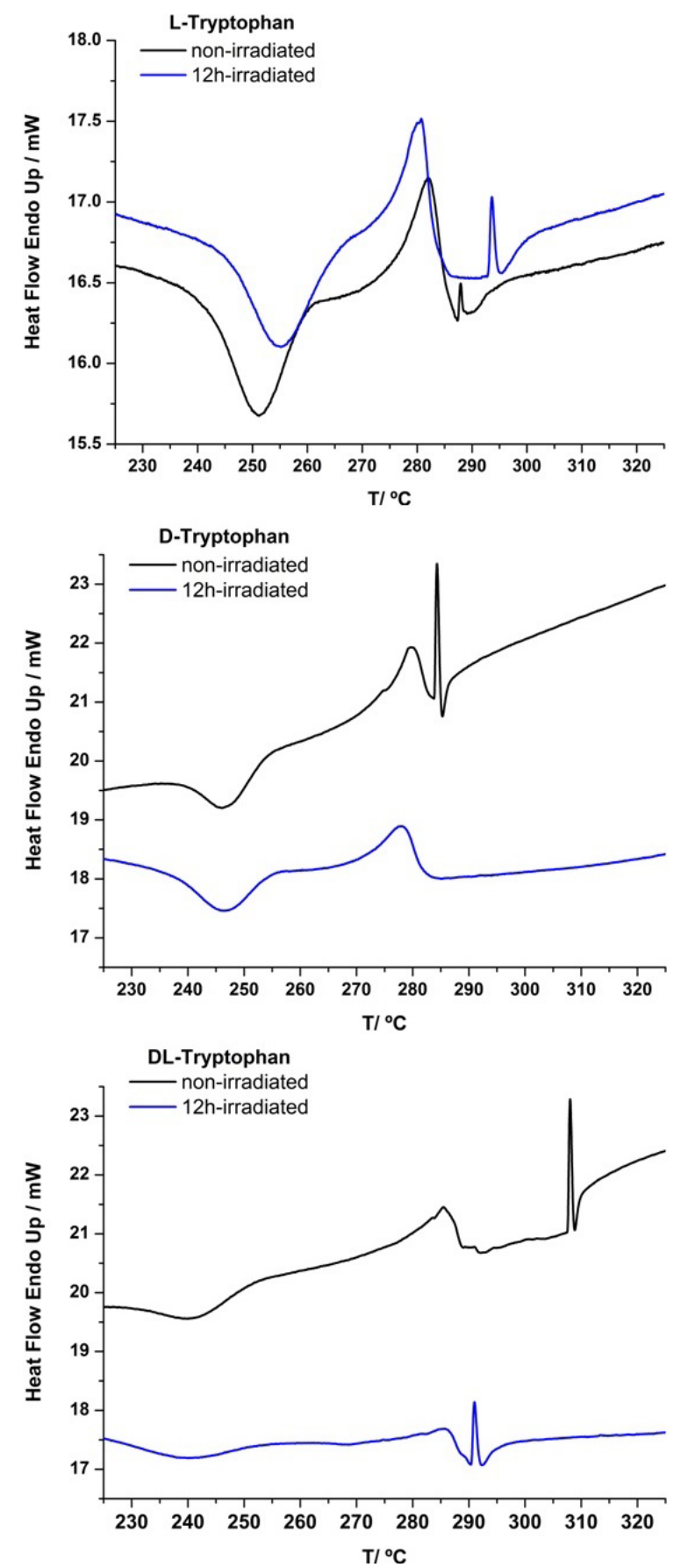

Fig. 3. DSC plots for non-irradiated and $12 \mathrm{~h}$-irradiated samples: L-, D- and DL-tryptophan.

An exothermic peak (1) is recorded first in the range $250-260{ }^{\circ} \mathrm{C}$ for $\mathrm{L}$ and $\mathrm{D}$ tryptophan and for the racemic in the range $240-250^{\circ} \mathrm{C}$. It is followed by two endothermic effects. The maxima of the first endothermic peak (2) of the three isomers are situated in the temperature range $280-290{ }^{\circ} \mathrm{C}$. As regards the second 
endothermic peak (3) it is different for the three isomers. This peak is situated around $287^{\circ} \mathrm{C}$ for the enantiomers and for the racemic mixture, at $307^{\circ} \mathrm{C}$.

The shape of the DSC thermograms greatly depends on the morphology of the samples. The presence of an exothermic peak observed with our samples is differing from the behavior in the case of samples taken directly from the bottle [26]. This situation is consistent with the dielectric investigation of premelt of amino acids by Matthews and Riga [27] who showed a clear difference between the neat samples, those heated prior to dielectric analysis, and those dried in a desiccator. Tryptophan is an interesting case because its neat and heat-treated samples showed no premelt peak. The absence of a premelt peak is typically associated with a greater amorphous content; in this case, it is possible that desiccation encouraged crystallization of our samples [28].

The endothermic peaks observed on the curves are due to melting accompanied by decomposition. The sensitivity of the onset temperature of peak 2 on the heating rate proves that it does not belong only to melting. The melting points usually found for most amino acids are irrelevant since they decompose, so that the "melting" points vary according to the experimental conditions used by the researcher [29].

The start temperatures of the melting - decomposition process of L-tryptophan reported in literature are divergent: $251{ }^{\circ} \mathrm{C}[30], 283{ }^{\circ} \mathrm{C}[31], 289.5^{\circ} \mathrm{C}$ [32], $297{ }^{\circ} \mathrm{C}$ [33], $268{ }^{\circ} \mathrm{C}[34], 290{ }^{\circ} \mathrm{C}$ [35], $268{ }^{\circ} \mathrm{C}$ [36], our value being $279^{\circ} \mathrm{C}$. Literature states that on heating, the main processes which occur are decarboxylation and oxidative deamination of tryptophan, forming tryptamine, indole-3-pyruvic acid and ammonia. The exposure of tryptophan to heat has also been shown to yield minimally soluble brown products that have not been characterized. At temperatures in the range $150-185^{\circ} \mathrm{C}$ and particularly in strongly alkaline media, partial or complete racemisation of tryptophan has been observed. At temperatures above $200{ }^{\circ} \mathrm{C}, \alpha$-carbolines and $\gamma$ carbolines were detected, but in much lower quantities than $\beta$-carbolines ( $\beta \mathrm{c}$ ) [37].

The characteristic temperatures and enthalpies of each endothermic step were calculated for samples before and after irradiation with different doses. The corresponding data are shown in Tables 2-3.

Table 2. DSC temperatures for L-, D-and DL-tryptophan non-irradiated and irradiated with different doses.

\begin{tabular}{|c|c|c|c|c|c|c|c|c|c|}
\hline \multirow{4}{*}{$\begin{array}{c}\text { Dose, } \\
\text { kGy }\end{array}$} & \multicolumn{9}{|c|}{ The melting/decomposition temperatures of tryptophan } \\
\hline & \multicolumn{3}{|c|}{ L-Trp } & \multicolumn{3}{|c|}{ D-Trp } & \multicolumn{3}{|c|}{ DL-Trp } \\
\hline & (exo) & & & (exo) & & & & & \\
\hline & $\mathbf{t}_{\text {onset1 } 1}{ }^{\circ} \mathbf{C}$ & $\mathbf{t}_{\text {onset } 2}{ }^{\circ} \mathbf{C}$ & $\mathbf{t}_{\text {onset3 } 3}{ }^{\circ} \mathbf{C}$ & $\mathbf{t}_{\text {onset } 1},{ }^{\circ} \mathbf{C}$ & 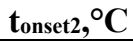 & $\mathbf{t}_{\text {onset } 3},{ }^{\circ} \mathbf{C}$ & $\mathbf{t}_{\text {onset } 1},{ }^{\circ} \mathbf{C}$ & $\mathbf{t}_{\text {onset } 2,}{ }^{\circ} \mathbf{C}$ & $\mathbf{t}_{\text {onset } 3},{ }^{\circ} \mathrm{C}$ \\
\hline 0 & 241 & 279 & 287 & 241 & 280 & 283 & 235 & 281 & 307 \\
\hline 0.63 & - & 291.61 & - & 238.12 & 280.06 & 281.88 & 231.4 & 279.53 & 283.92 \\
\hline 1.26 & - & 287.6 & - & 238.52 & 277.99 & - & 232.77 & 281.81 & 290.52 \\
\hline 2.52 & - & 289.56 & - & 238.82 & 278.39 & 295.37 & 231.51 & 272.98 & 316.13 \\
\hline 5.04 & - & 289.54 & - & 239.65 & 278.64 & 299.04 & 233.46 & 274.71 & 297.91 \\
\hline 7.56 & 247.68 & 275.5 & 293.04 & 238.86 & 278.17 & - & - & 281.33 & 290.51 \\
\hline
\end{tabular}

Table 3. Decomposition enthalpy for tryptophan isomers non-irradiated and irradiated with different doses.

\begin{tabular}{|c|c|c|c|c|c|c|c|c|c|}
\hline \multirow{3}{*}{$\begin{array}{c}\text { Dose, } \\
\text { kGy }\end{array}$} & \multicolumn{9}{|c|}{ The decomposition enthalpies, $\Delta H,\left(\mathrm{~kJ} \mathrm{~mol}^{-1}\right)$} \\
\hline & \multicolumn{3}{|c|}{ L-Trp } & \multicolumn{3}{|c|}{ D-Trp } & \multicolumn{3}{|c|}{ DL-Trp } \\
\hline & $\begin{array}{c}\Delta H_{1}, \\
(\mathbf{k J} \\
\left.\mathbf{m o l}^{-1}\right)\end{array}$ & $\begin{array}{c}\Delta H_{2}, \\
(\mathbf{k J} \\
\left.\mathrm{mol}^{-1}\right)\end{array}$ & $\begin{array}{c}\Delta H_{3} \\
\left(\mathbf{k J}^{-1}\right. \\
\left.\mathrm{mol}^{-1}\right)\end{array}$ & $\begin{array}{c}\Delta H_{1}, \\
(\mathbf{k J} \\
\left.\mathbf{m o l}^{-1}\right)\end{array}$ & $\begin{array}{c}\Delta H_{2}, \\
(\mathbf{k J} \\
\left.\mathbf{m o l}^{-1}\right)\end{array}$ & $\begin{array}{c}\Delta H_{3} \\
\left(\mathbf{k J}^{-1}\right) \\
\left.\mathrm{mol}^{-1}\right)\end{array}$ & $\begin{array}{c}\Delta H_{1}, \\
(\mathbf{k J} \\
\left.\mathbf{m o l}^{-1}\right)\end{array}$ & $\begin{array}{c}\Delta H_{2}, \\
(\mathbf{k J} \\
\left.\text { mol }^{-1}\right)\end{array}$ & $\begin{array}{c}\Delta H_{3} \\
(\mathbf{k J} \\
\left.\mathrm{mol}^{-1}\right) \\
\end{array}$ \\
\hline 0 & -51.0 & 38.8 & 1.1 & -33.3 & 28.4 & 6.4 & -50.3 & 54.6 & 7.1 \\
\hline 0.63 & - & 62.52 & - & -49.67 & 15.17 & 1.18 & -40.20 & 11.06 & 2.97 \\
\hline 1.26 & - & 63.76 & - & -55.75 & 40.55 & & -34.90 & 12.85 & 4.70 \\
\hline 2.52 & - & 64.07 & - & -52.67 & 41.89 & 4.60 & -42.01 & 40.19 & 5.78 \\
\hline 5.04 & - & 64.47 & - & -49.04 & 52.56 & 4.56 & -45.75 & 34.65 & 7.34 \\
\hline 7.56 & 106.01 & 35.71 & 2.85 & -53.61 & 30.27 & & -68.79 & 18.84 & 1.61 \\
\hline
\end{tabular}


DSC data of Tables 2-3 show a decrease of the values of thermochemical parameters between nonirradiated and irradiated samples and evidence at the same time little variation between irradiated samples with different doses, resulting in radiation stability in the range (0.63-7.56) $\mathrm{kGy}$.

A different behavior on heating after irradiation is observed in the case of L-tryptophan, compared to the other stereoisomers. First, the exothermic peak disappears after irradiation of this isomer with small doses, probably because of a crystallization process. The premelting process reappears at larger doses ( $7.56 \mathrm{kGy})$. This process becomes more important at higher doses for the other stereoisomers (larger peaks) as well. Secondly, the temperature of the first endothermic peak of L-tryptophan tends first to increase with irradiation then to decrease, while the second tiny peak disappears after low doses of irradiation and reappears at larger ones. The temperature of the first endothermic peak slightly decreases for stereoisomer -D while an important increase with the dose is registered in the temperature of peak 3 at small doses of irradiation. The temperature of the second peak of the racemic decreases first with the dose and tends to come back to the initial value when the dose rises. The temperature of the third peak of this stereoisomer (higher than that of enantiomers) tends to decrease after irradiation. (Table 2).

The variation of the transformation temperatures of irradiated samples is explained by the effect of the irradiation products acting as impurities. In the case of irradiated amino acids the network of ionic interactions of zwitterions is partially destroyed. The possibility of an increase in the peak temperature in the case of irradiated samples with higher doses is due to the accumulation of radiolysis products. As a consequence, the irradiation products have a protective role on the amino acid parent molecule.

Wickern et al. [38] have noted that peroxyl radicals are produced along with hydroxyl radicals in the presence of oxygen, and that tryptophan radicals and peroxy compounds are presumed to be intermediates in the radiolytic degradation process.

The weight loss during the DSC runs of irradiated and non-irradiated stereoisomers shows that samples irradiated with lower doses loose more weight than those with higher doses (Figure 4). This behavior may be explained by the same mechanism of the protective effect of the irradiation products, mentioned above.

The main organic group which leads to the degradation of tryptophan is carbonyl. The initial reaction is a condensation with the primary amine, forming a Schiff base. This initial reaction was able to be inhibited by attaching a substituent to the amine (e.g. alkyl, carbonyl), which in turn inhibited all of the subsequent degradation pathways, e.g. Maillard reactions and formation of degradation products that occur following the Schiff base formation [39].

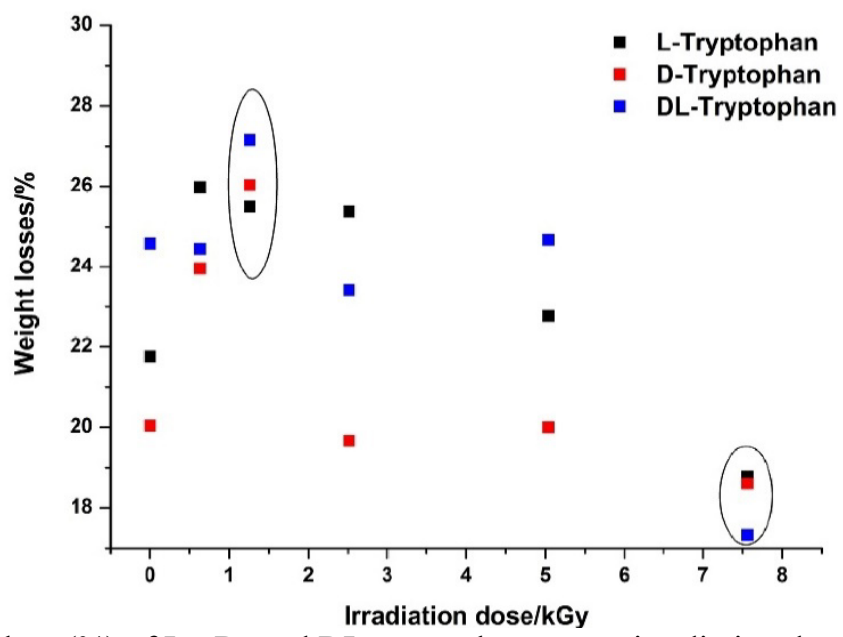

Fig. 4 Plot of the weight loss (\%) of L-, D- and DL-tryptophan versus irradiation dose (kGy). 
Determination of purity by DSC was performed using the PerkinElmer Pyris DSC purity analysis software permitting the assessment of purities for samples which undergo simultaneous degradation during melting. The purity of a sample for which only the molecular weight and sample weight are known can be ascertained by a simple mathematical treatment of the data from a DSC scan.

Purity determination by DSC is based on the fact that impurities lower the melting point of a eutectic system in a predictable way as described by the van't Hoff equation (1).

$$
1 / \mathrm{F}=[\Delta H / R] \cdot\left[T_{0}-T_{s}\right] / T_{0}^{2} \cdot\left[1 / X_{2}\right]
$$

$\mathrm{T}_{\mathrm{s}}$-sample temperature and the melting temperature $/ \mathrm{K}, \mathrm{T}_{0}$-the melting temperature of the pure substance $/ \mathrm{K}, \Delta \mathrm{H}$-heat of melting of the pure material $/ \mathrm{J} / \mathrm{g}, \mathrm{X}_{2}$-mole fraction of impurity in the sample, R-constant $(8,314 \mathrm{~J} / \mathrm{mole} \cdot \mathrm{K}), \mathrm{F}_{\mathrm{s}}$-fraction of sample melting at temperature $\mathrm{T}_{\mathrm{s}}$

$$
\mathrm{F}_{\mathrm{s}}=\frac{\mathrm{A}_{\mathrm{s}}}{\mathrm{A}_{\mathrm{t}}}
$$

$A_{s}$-area of the melting endotherm up to temperature $T_{s}, A_{t}$-total area of melting endotherm.

For purity measurements, the sample was heated through its melting range. The area of the resulting melting endotherm, obtained by integration, corresponds to the enthalpy of fusion. The van't Hoff linear relationship is graphically presented by plotting the different sample temperatures against the reciprocal of each of their melted fractions. A nonlinear least-squares technique was used to approximate the area increment to correct both the total and each of the fractional areas prior to obtain a straight line. The slope and intercept of the $T_{s}$ versus the corrected $1 / F$ curve was obtained by a least-square fit to a straight line. The sample impurity, obtained from the slope of the curve, was converted into sample purity (1-impurity) [40].

In Fig. 5 is plotted the purity using Pyris software for L-tryptophan $12 \mathrm{~h}$-irradiated (1.26 kGy).

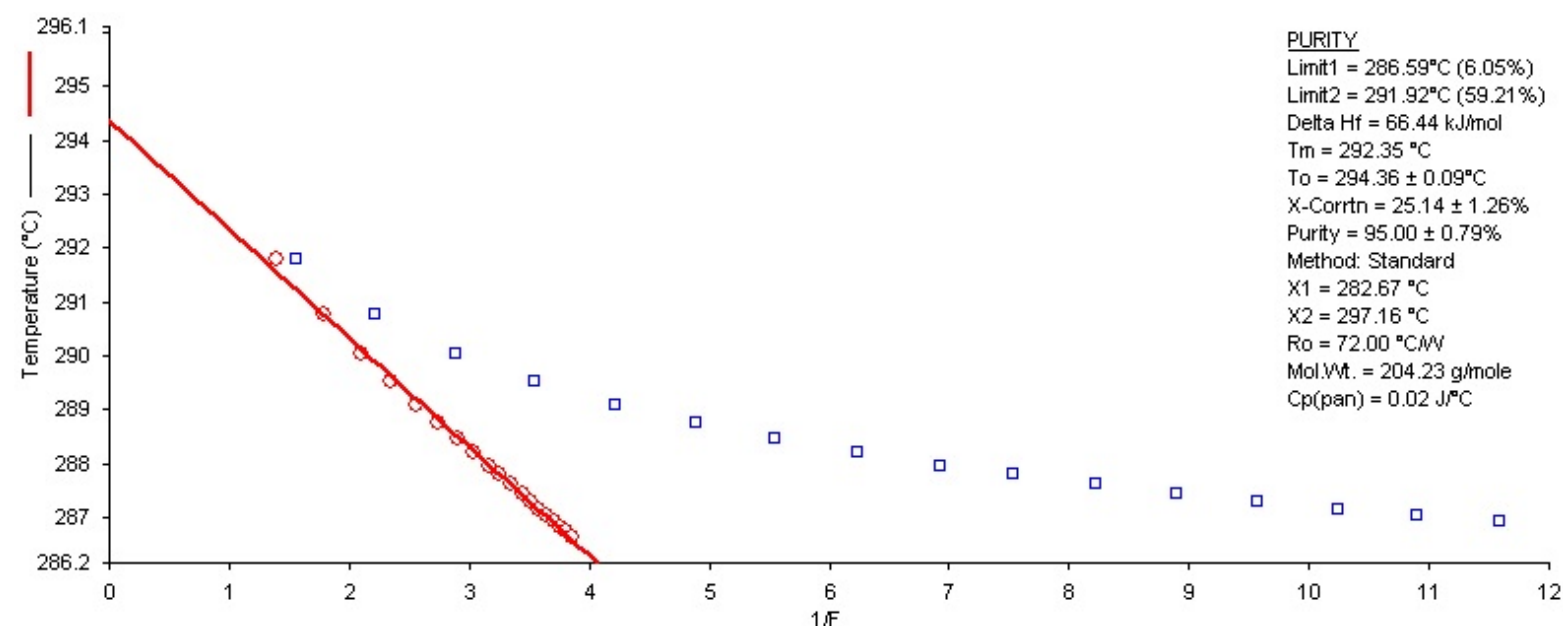

Fig. 5 Van't Hoff plot for 12h-irradiated (1.26 kGy) L-tryptophan.

In the $T$ vs $1 / F_{s}$ curve, the corrected data points are shown as red circles and the line drawn through them shows how the data fit the van't Hoff relationship Eq. (2). The blue boxes represent the uncorrected values calculated for $1 / \mathrm{F}_{\mathrm{s}}$ (fraction melted) at given temperatures.

Data of Table 4 show the obtained purities of tryptophan with increasing irradiation dose. 
Table 4. Variation of the purity, \% versus irradiation dose for tryptophan isomers.

\begin{tabular}{|c|c|c|}
\hline Compound & Dose, kGy & Purity, $\%$ \\
\hline \multirow{4}{*}{ L-Trp } & 0 & 99.17 \\
\cline { 2 - 3 } & 0.63 & 97.05 \\
\cline { 2 - 3 } & 1.26 & 95.00 \\
\cline { 2 - 3 } & 2.52 & 95.67 \\
\cline { 2 - 3 } & 5.04 & 96.42 \\
\cline { 2 - 3 } & 7.56 & 97.96 \\
\hline \multirow{5}{*}{ D-Trp } & 0 & 98.27 \\
\cline { 2 - 3 } & 0.63 & 98.55 \\
\cline { 2 - 3 } & 1.26 & 94.21 \\
\cline { 2 - 3 } & 2.52 & 99.24 \\
\cline { 2 - 3 } & 5.04 & 99.85 \\
\cline { 2 - 3 } & 7.56 & 97.33 \\
\hline \multirow{5}{*}{ DL-Trp } & 0 & 98.91 \\
\cline { 2 - 3 } & 0.63 & 99.73 \\
\cline { 2 - 3 } & 1.26 & 97.78 \\
\cline { 2 - 3 } & 2.52 & 99.19 \\
\cline { 2 - 3 } & 5.04 & 98.94 \\
\cline { 2 - 3 } & 7.56 & 98.23 \\
\hline
\end{tabular}

It can be seen from data of Table 4 that the purity of the investigated isomers of tryptophan is not greatly affected by irradiation with low doses (0.63-7.56 kGy). The amount of the radiolytic products is not high enough to destroy the crystalline lattice. Large doses of irradiation can lead to the formation of decomposition products and consequently to a weight loss.

For tryptophan isomers a correlation was found between the irradiation dose and the shifts in DSC curves and the loss of content determined by the HPLC method.

\section{Conclusion}

Like all chemicals, pharmaceuticals and adjuvants, can undergo chemical changes under the influence of radiation. Thus, each system must first be rigorously studied to examine the chemical changes induced and to establish the maximum tolerated dose. Studies on the influence of irradiation dose are necessary to endure long-term stability and to demonstrate that there is no loss of potency or harmful pharmacological change produced by the selected dose.

The methods applied in the present work are suitable for investigation of the effect of ionising radiation sterilization on tryptophan containing foods and drugs. The small changes taking place under the influence of irradiation could be explained by a similarity of the physical-chemical properties of the parent compounds and those of irradiated ones.

Data obtained by the HPLC method reveal however differences in the content of the active substance in the samples before and after irradiation because this method enables a separation of the parent compounds from the products of their radiolysis.

Therefore, it must be checked whether this type of sterilization does not produce changes in its physicochemical properties or does not cause a significant loss of content, which affect the therapeutic effect. Based on the obtained results, it was ascertained that MS-MS spectroscopy technique is appropriate to be employed as an important method in monitoring the radiosterilization of tryptophan isomers and/or pharmaceutical delivering systems containing tryptophan as main ingredient. 
The changes detected by DSC correspond to the differences indicated by HPLC i.e., a small mass loss of the active substance, which means that tryptophan isomers are resistant to ionising radiation (radiochemical stability) thus being safely subjected to sterilisation by irradiation.

\section{Acknowledgments}

Support of the EU (ERDF) and Romanian Government, that allowed for acquisition of the research infrastructure under POSCCEO 2.2.1 project INFRANANOCHEM - Nr. 19/01.03.2009, is gratefully acknowledged.

\section{References}

1. Sidransky H. CRC Series in Modern Nutrition; 2002.

2. IUPAC-IUB Joint Commission on Biochemical Nomenclature, 1983.

3. Friedman, M. Intl. J. Trp. Res. 2018, 11, 1-12.

4. Ahmad, F.; Moat, A.G. J. Biol. Chem. 1966, 241,775-80.

5. Pallaghy, P.K.; Melnikova, A.P.; Jimenez, E.C.; Olivera, B.M.; Norton, R.S. Biochem. 1999, 38, 11553-9.

6. Kantoglu, O.; Guven, O. Nucl. Instr. Meth. Phys. Res. B. 2002, 197, 259-264.

7. Stubbe, J. A. Annu. Rev. Biochem. 1989, 58, 257-263.

8. Davies, M. J.; Fu, S.; Dean, R. T. Biochem. J. 1995, 305, 643-647.

9. Van der Zee, J. Biochem. J. 1997, 322, 633-640.

10. Ban, F.; Gauld, J.W.; Boyd, R.J. J. Phys. Chem. 2000, 104, 5080-5085.

11. Cherubini, C.; Ursini, O. Springer Plus. 2015, 4, 541-551.

12. Neacsu, A.; Contineanu, M.; Zaharescu, T.; Contineanu, I. Rev. Chim. 2016, 67, 1745-1750.

13. Contineanu, M.; Perisanu, St.; Neacsu, A. Analls Univ. Bucharest. 2010, 19, 69-77.

14. Ayodhya, D.; Venkatesham, M.; Santoshi, A.; Kumara, G.; Reddy, B.; Veerabhadram, G. Int. J. Ind. Chem. 2015, 6, 261-271.

15. Baran, J.A.; Drozd, M.A.; Ratajczak, H. J. Mol. Struct. 2010, 976, 226-42.

16. Sadhasivam, B.;Muthusamy, S. Des. Monomers Poly. 2016, 19, 236-247.

17. Baran, J.A.; Ratajczak, H. Vib. Spectrosc. 2007, 43, 125-39.

18. Nakamoto, K., in Infrared and raman spectra of inorganic and coordination compounds, part A: theory 458 and applications in inorganic chemistry, John Wiley \& Sons, Inc., USA, 2009, 279-281.

19. Cao, X.; Fischer,G. J. Phys. Chem. A. 1999, 103, 9995-10003.

20. Sagstuen, E.; Sanderud, A.; Hole, E. O. Radiat. Res. 2004, 162, 112-118.

21. Iglesias-Groth, S.; Cataldo, F.; Ursini, O.; Manchado, A. Mon. Not. R. Astron. Soc. 2011, 410, $1447-$ 1453.

22. Yamada, K.; Miyazaki, T.; Shibata, T.; Hara, N.; Tsuchiya, M. J. Chrom. B. 2008, 867, 57-61.

23. Cech, N.B.; Enke, C.G. Mass Spectrom. Rev. 2001, 20, 362- 387.

24. Ravenscroft, G.; Stephen, M.J.; Colley, K.R.; Clement, S.; Bringans, S.; Lipscombe, R.; Fabian, V.A.; Laing, N.G.; Nowak, K.J. Neuromuscular Disorders. 2008, 18, 953-958.

25. Marciniek, B.; Kozak, M.; Naskrent, M.; Hofman, M.; Dettlaff, K.; Stawny, M. J. Therm. Anal. Calorim. 2010, 102, 261-266. 
26. Gheorghe, D.; Neacşu, A.; Contineanu, I.; Tănăsescu, S.; Perişanu, S. J. Therm. Anal. Calorim. 2017, 130, 1145-1152.

27. Mathews, M.E.; Riga, A.T. J. Therm. Anal. Calorim. 2009, 96, 673-6.

28. Matthews, M.E.; Atkinson, I.; Presswala, L.; Najjar, O.; Gerhardstein, N.; Wei, R.; Rye, E.; Riga, A.T. J. Therm. Anal. Calorim. 2008, 93, 281-7.

29. Wesolowski, M.; Erecinska, J. J. Therm. Anal. Calorim. 2012, 109, 585-593.

30. Schaberg, A.; Wroblowski, R.; Goertz, R. 3rd European Symposium on Fire Safety Science IOP Publishing, IOP Conf. Series: J. Phys.: Conf. Series. 2018, 1107-1112.

31. Cataldo, F.; Ragni, P.; Groth, S.I.; Manchado, A. J. Radioanal Nucl. Chem. 2011, 287, 903-911.

32. Wesolowski, M.; Erecinska, J. J. Therm. Anal. Calorim. 2005, 82, 307-13.

33. Rodante, F.; Marrosu, G.; Catalani, G. Thermochim. Acta. 1992, 194,197-213.

34. Rodriguez-Mendez, L.; Rey, F.J.; Martin-Gil, J.; Martin-Gil, F.J. Thermochim. Acta. 1988, 134,73-8.

35. Weast, R.C., in: CRC Handbook of chemistry and physics, 58-th Edition 1977-1978, Cranwood Parkway, Cleveland, Ohio 44128, C-534.

36. Bryan, A. M.; Olafsson, P. G. Anal. Lett. 1969, 2, 505-513.

37. Friedman, M.; Cuq, J.L. J. Agric. Food Chem. 1988, 36, 1079-1093.

38. Wickern, B.; Muller, B.; Simat, T.; Steinhart, H. J. Chromatogr. A. 1997,786, 57-65.

39. Bellmaine, S.; Schnellbaecher, A.; Zimmer, A. Free Radical Biol. Med. 2020, 160, 696-718.

40. Kestens, V.; Auclair, G.; Drozdzewska, K.; Held, A.; Roebben, G.; Linsinger, T. J. Therm. Anal. Calorim. 2010, 99, 245-261. 